\title{
A Memetic Approach to the Use of Bilingual Signs
}

\author{
Zhan Wang \\ Department of Foreign Languages, Nanjing University of Finance and Economics, Nanjing 210046, China \\ Tel: 86-25-8349 5712 E-mail: zhwangfun@163.com
}

This work was supported by the Fund for Scientific Research from Nanjing University of Finance and Economics under Grant No. B0544

\begin{abstract}
This paper first investigates the relationship between memes and public signs and then discusses the imitation of public signs as memes and finally explores the feasibility of meme therapy, an analogy with gene therapy, that is, English words and expressions most frequently used in public signage are imitated or copied for the purpose of correct use of bilingual signs.
\end{abstract}

Keywords: Bilingual signage, Memes and imitation, Meme therapy, Standardization

\section{Introduction}

To help tourists, many cities in China have set up information signs in Chinese and English at the public places, such as airport, railway station, bus stops, main streets, shops, scenic spots, museums, parks and hotels. But difficulty to understand bilingual signs is the worst problem in terms of language environment in some big cities. Many tourists from English speaking countries think the English translations do not give as much information as their Chinese equivalents. In order to eliminate language barriers and provide a fine, standardized service for domestic and foreign tourists, we are expected to have a high sense of international communication and language used in public signs should all meet international standards.

\section{Memes and Imitation}

In our attack on the problem, we take the memetic theory of Dawkins as our starting point. The term meme was coined by Dawkins, who described memes as units of cultural transmission which "propagate themselves in the meme pool by ... a process which, in the broad sense, can be called imitation" (Dawkins, 1976, p.206). He said: "examples of memes are tunes, ideas, catch-phrases, clothes fashions, ways of making pots or of building arches" (Dawkins, 1976, p.206); "a meme should be regarded as a unit of information residing in a brain... It has a definite structure, realized in whatever physical medium the brain uses for storing information.” (Dawkins, 1982, p.109); "The phenotypic effects of a meme may be in the form of words, music, visual images, styles of clothes, facial or hand gestures...”(Dawkins, 1982, p.109). In a general way, Dawkins' initial treatment of memes is still how memes are principally conceived. The Oxford English Dictionary defines a meme as follows: "meme (mi:m), n. Biol. (shortened from mimeme ... that which is imitated, after GENE n.). An element of a culture that may be considered to be passed on by non-genetic means, esp. imitation".

The dictionary definition, and Dawkins's original conception of the meme, both include the critical point that memes are cultural information that is copied, and that it is copied by imitation. And the psychologist, Thorndike (1898), was possibly the first to provide a clear definition of imitation as "learning to do an act from seeing it done". Thorndike's definition captures the essential idea that in imitation a new behaviour is learned by copying it from someone else. Blackmore (1998) argued that "the definition of the meme depends on, and should depend on, the concept of imitation. Therefore, only those things that can be passed on by imitation should count as memes." If we stick with the original definition of the meme as transmitted by imitation, then public signs passed on by this copying process are memes.

\section{Problems}

Bilingual signs are quite helpful to non-Chinese speaking people working and living in China. But many existing bilingual signs are funny and mistranslated, which is not rare in public places. In the following chart, the incorrect signs in need of a massive improvement are now in use and can be found in many cities, and the idiomatic signs used in English speaking countries are their equivalents.

The incorrect signs that can be seen in many Chinese cities hardly make sense and are unable to assist foreigners. And this state of confusion is shared by many visitors to China. Measures must be adopted to settle the confusion of the current public signs in English. From the China Daily website, we learn that a campaign named "Use Accurate English 
to Welcome the Olympics---Public Bilingual Sign Standardization Drive” is launched. The campaign is aimed at improving the country's international image by using correct English on bilingual signs and correcting existing bilingual public signs and printed materials as the website says. Hopefully the utilization of English equivalents that are most frequently used for public signs used internationally is one of the effective answers. It is helpful at least to some extent for the common mistakes to be corrected easily.

\section{Public Signs as Memes}

We believe that the memetic approach has much to offer in the area of language using and therefore we have tried to explore the correct use of public signs, which is based on its main concepts. All transmitted knowledge is memetic. An idea or information pattern is not a meme until it causes someone to replicate it, to repeat it to someone else. Dawkins (1976) suggested three conditions of a meme that gave it a high survival value: fidelity, fecundity, and longevity. In other words, a good meme must be copied accurately, many copies must be made, and the copies must last a long time. Commonly-used public signs satisfy all three of the necessary conditions and act as dynamic memes. Memes pass information across populations, and, we think, can also be used to fulfil the same role with necessary involvement of human intentionality.

\section{Meme Therapy}

It is a truism to point out that Chinese is exotic to the English language-culture substructure, which means that there is a massive linguistic distance between English and Chinese. And the fact is that native speakers have a vast store of public signs. When it comes to language use, perhaps it might be useful for us to take the meme's point of view and consider them as a meme pool ready to be used to produce accurate and meaningful bilingual signs. Common English signs in public places from English-speaking countries can, and should be used by imitation, as when the shape of a manuscript submitted to Asian Social Science is meticulously copied, a memetic approach.

Just as gene therapy which is used as an effective strategy to disease treating, we examine the potential of using common public signs for error or mistake correcting, which we call meme therapy, an analogy with gene therapy. This implies a shift from gene therapy as a practical gene transfer method to a new type of language therapy: the introduction of commonly used English into bilingual signs. As the memetic approach suggests, the correct sign produces another sign, its interpretant (then another, and so on), to represent the same reality, or, in some cases, a closely related reality. A good case in point is offered as follows.

We know that Scotland's smoking ban in enclosed public places (including pubs and restaurants, and public transport) takes effect on March 26, 2006. And besides Smoke-free Scotland, the detailed guidance on smoking policies, we find that copies of sample signage are provided and can be downloaded from www.clearingtheairscotland.com. On the one hand, it will be an easy and effective practice for those who have difficulty in developing their own signs to have the copies of sample signage which can be imitated and used readily. And on the other hand, in this way, the "NO SMOKING” sign, a useful meme, is more likely to be used effectively and spreads successfully.

\section{Practical Application}

\subsection{Keep Distance Meme}

What follows is written by Jay Shen (2006), who is from United States: "The first English sign that caught my eyes when I just arrived in Beijing was a traffic sign along the airport freeway, it reads: 'keep space'. I believe that it is to warn the drivers not to get too close to the vehicles ahead, so as not to kiss the ass of another vehicle. However, space refers to an area with two or three dimensions, such as in 'space shuttle'. The correct word should be 'distance' that refers to the length between two points. This traffic sign is greeting every single person arriving in Beijing for at least fifteen years..."

The incorrect English sign is not regular English by common sense, or simply wrong. Travelers from English speaking countries get the first impression of a city after they step down the foot ladder of the airplane and get into a taxi, or walk out of the railway station and into the subway. If we are giving the city a facelift, signs of this type are in great need of improvement. The simplest way to change the present awkward situation is to copy the Keep Distance meme directly.

\subsection{No Swimming Meme}

There is a newly-posted sign at the side of a lake in a scenic spot in Nanjing. It reads "OR YOUR SATETY, DO NOR SWIM IN THE PURPLE CLOUDS CAKE, NOLATORS SHALL BEAR ALL SONSEQUENCES OF THEIA ACTONS!" which means "For your safety, do not swim in the purple clouds lake. Violators shall bear all consequences of their actions". Such simplest spelling errors in English signage happen because there is no uniform criterion for bilingual use and people are negligent when translating.

A good sign in this context should draw attention to itself and then convey its message as clearly as possible. In English speaking countries a similar sign would simply read: "No Swimming!" The No Swimming meme used here is a recognizable transcription of components of the original script. It is very easy to reproduce, and due to its brevity the 
copying fidelity can be very high. Ted Utoft (2005) said that many people coming to China do not speak Chinese, but English may not be their first language either, and their knowledge of English may be limited. Therefore, keeping the language simple makes the signs much more effective in addressing the warning or behaviour that the sign dictates.

\section{Conclusion}

What we have tried to do in this paper is to take the memetic approach to the use of public signs in English. The value of meme therapy is demonstrated by analyzing how public signage is typically used both in China and in English speaking countries. In that way we show that in most cases a word-for-word translation does not help, when previously perhaps it is thought that it might do to sling together a few words picked up from the dictionary.

Meme therapy is readily applied for the purpose of correcting common mistakes in translated signage and a lot of time and effort in creating bilingual signs will be saved. Also, it is a great help in using the English signs appropriately and accurately and it is beneficial to the official agencies concerned for a better regulation of China's public signs in English.

The adoption of meme therapy has the potential to improve and standardize bilingual signs in China. We hope our contribution will stimulate further efforts of both the research and applications of the memetic theory.

\section{References}

Blackmore, S. (1998). Imitation and the definition of a meme. Journal of Memetics - Evolutionary Models of Information Transmission. 2. [Online] Available: http://jom-emit.cfpm.org/1998/vol2/balckmore_s.html (August 8, 2006)

Dawkins, R. (1976). The Selfish Gene. Granada Paladin: London. p206.

Dawkins, R. (1982). The Extended Phenotype. Oxford University Press: Oxford. p109.

Jay Shen. (2006).The English Signs in Beijing. [Online] Available:

http://language.chinadaily.com.cn/herewego/news_content.shtml?id=229 (November 15, 2007)

Ted Utoft. (2005). Keeping the language simple makes the signs much more effective. [Online] Available: http://language.chinadaily.com.cn/herewego/news_content.shtml?id=11 (November 15, 2007)

Thorndike, E.L. (1898). Animal intelligence: An experimental study of the associative processes in animals. Psychological Review Monographs. 2. No 8.

Table 1. Comparison between incorrect signs and idiomatic signs.

\begin{tabular}{|l|l|}
\hline Incorrect Signs & Idiomatic Signs \\
\hline A Forest Is Prevented Fires & $\begin{array}{l}\text { FIRE, NAKED FLAME \& SMOKING } \\
\text { PROHIBITED }\end{array}$ \\
\hline Collecting money toilet & Pay toilet \\
\hline Don't Fall! & Watch your step \\
\hline Flower Room Visitor Stop & Staff Only \\
\hline $\begin{array}{l}\text { Little grass is smiling slightly, please walk on the } \\
\text { pavement. }\end{array}$ & Keep off the grass \\
\hline Office area, please do not coming. & Staff Only \\
\hline Preserve green grass and retain the green color & Keep off the grass \\
\hline Stop cashier & Cashier Closed \\
\hline
\end{tabular}

